\title{
ANALISIS EFEKTIVITAS PENUKAR KALOR PIPA HELIKAL DESTILASI MINYAK ATSIRI KAYU PUTIH
}

\author{
Antonius Hatumessen ${ }^{1 *}$, Nicolas Titahelu ${ }^{2}$, Cendy Sophia Tupamahu ${ }^{3}$ \\ 1Jurusan Teknik Mesin Fakultas Teknik Universitas Pattimura, Ambon, 97233 \\ *Email: tonihatumessen@yahoo.com \\ 2Jurusan Teknik Mesin Fakultas Teknik Universitas Pattimura, Ambon, 97233 \\ Email: titahelun@gmail.com \\ 3Jurusan Teknik Mesin Fakultas Teknik Universitas Pattimura, Ambon, 97233 \\ Email: tupamahucendy@gmail.com
}

\begin{abstract}
Abstrak. Tanaman kayu putih merupakan salah satu tanaman penghasil minyak atsiri. Pengolahan minyak kayu putih pada umumnya menggunakan metode destilasi. Destilasi minyak kayu putih yang digunakan secara tradisional menggunakan kondensor pipa lurus. Kelemahan dari kondensor pipa lurus yakni suhu kondensat yang keluar masih sangat tinggi,hal ini menunjukan bahwa efektivitas kondensor pipa lurusbelum optimal. Untuk mengoptimalkan efektivitas kondensor sistem destilasi, maka dirancang sebuah kondensor dengan tipe kondensor pipa helikal pada sistem destilasi minyak atsiri. Pada penelitian ini akan memvariasikan rasio perbandingan jarak pitch terhadap diameter pipa kondensor, yang mana bertujuan untuk mendapatkan rasio pitch helikal koil yang efektif untuk mengoptimalkan efektivitas kondensor pipa helikal. Penelitian ini menggunakan metode simulasi pada COMSOL Multiphysics 5.4. Varian rasio pitch yang digunakan yakni sebesar 2,$1 ; 2,62 ; 3,15 ; 3,67 ; 4,2$. Parameter yang dikonstankan pada penelitian ini adalah suhu fluida masuk pada sisi tube $373 \mathrm{~K}$, suhu fluida masuk pada sisi shell $288 \mathrm{~K}$, kecepatan masuk fluida pada sisi tube $0,2 \mathrm{~m} / \mathrm{s}$, dan kecepatan masuk fluida pada sisi shell $1 \mathrm{~m} / \mathrm{s}$. Hasil dari simulasi dengan memvariasikan rasio pitch menunjukan efektivitas meningkat seiring menurunnya nilai rasio pitch, dimana efektivitas tertinggi ditunjukan pada rasio pitch 2,1 dengan 75,9\% dan efektivitas terendah ditunjukan pada rasio pitch 4,2 dengan $70,7 \%$.
\end{abstract}

Kata kunci: Penukar kalor, pipa helikal, rasio pitch

\begin{abstract}
Eucalyptus plant is one of the essential oil-producing plants. Eucalyptus oil processing generally uses the distillation method. Traditionally used eucalyptus oil distillation uses a straight pipe condenser. The weakness of the straight pipe condenser is that the temperature of the condensate that comes out is still very high, this shows that the effectiveness of the straight pipe condenser is not optimal. To optimize the effectiveness of the distillation system condenser, a condenser with a helical pipe type condenser is designed in the essential oil distillation system. This study will vary the ratio of the pitch distance to the diameter of the condenser pipe, which aims to obtain an effective helical coil pitch ratio to optimize the effectiveness of the helical pipe condenser. This study uses the simulation method on COMSOL Multiphysics 5.4. The pitch ratio variant used is $2.1 ; 2.62 ; 3.15 ; 3.67 ; 4.2$. The parameters that are constant in this study are the inlet fluid temperature on the tube side $373 \mathrm{~K}$, the inlet fluid temperature on the shell side $288 \mathrm{~K}$, the fluid inlet velocity on the tube side $0.2 \mathrm{~m} / \mathrm{s}$, and the fluid inlet velocity on the shell side $1 \mathrm{~m} / \mathrm{s}$. The results of the simulation by varying the pitch ratio show that the effectiveness increases as the pitch ratio value decreases, where the highest effectiveness is shown at pitch ratio of 2.1 which $75.9 \%$ and the lowest effectiveness is shown to pitch ratio of 4.2 which $70.7 \%$.
\end{abstract}

Keywords: Heat exchanger, helical pipe, pitch ratio 


\section{PENDAHULUAN}

Pengolahan minyak atsiri dari tanaman kayu putih banyak ditemukan di kepulauan Maluku. Minyak atsiri kayu putih sering digunakan sebagai pengobatan alternatif. Hal tersebut dikarenakan komponen utama minyak atsiri yakni sineol termasuk dalam golongan terpenoid. Sineol merupakan senyawa monoterpene yang mana berperan sebagai antimikroba, antioksidan kekebalan tubuh, analgesic dan spasmolitik.

Metode yang digunakan dalam pengolahan minyak atsiri kayu putih yakni metode destilasi. Pada sistem destilasi terdapat dua komponen utama yakni boiler sebagai tempat mengkukus produk dan kondensor sebagai tempat untuk mendinginkan uap hasil kukusan. Model kondensor pada sistem destilasi yang ada didaerah kepulauan maluku masih menggunakan model kondensor pipa lurus, dimana terdapat kelemahan dari model ini yaitu suhu kondesat yang masih tinggi. Hal ini menunjukan bahwa kinerja kondensor belum optimal.

Berdasarkan riset yang dilakukan terhadap perbandingan penukar kalor pipa lurus dan pipa helical, diketahui bahwa penukar kalor pipa helikal lebih efektif dari penukar kalor pipa lurus.Beberapa penelitian terdahulu telah dilakukan untuk mengoptimalkan kinerja dari kondensor. Moawed, M.[1] melakukan penelitian terhadap fenomena konveksi alami pada penukar kalor pipa helikal dengan posisi vertikal dan horizontal. Fernández-Seara, et al.[2] melakukan analisis secara numerik kinerja penukar kalor pipa helikal dan melakukan validasi dengan data eksperimental.Alimoradi \& Veysi.[3] melakukan melakukan perhitungan terhadap laju perpindahan panas dan pembangkitan entropi untuk perpindahan panas konveksi paksa pada pipa helikal, dimana nilai kritis dan nilai optimal dicari untuk meningkatkan nilai COP (laju perpindahan panas per entropi yang dibangkitkan). Xu, X. et al.[4] menganalisis secara teoritis mekanisme perpindahan panas pada penukar kalor pipa helikal, hasilnya menunjukan bahwa efektivitas penukar kalor pipa helikal sangat tinggi karena gerakan aliran sekunder yang tegak lurus terhadap aliran utama yang disebabkan oleh gaya sentrifugal dari fluida. Mirgolbabaei, H.[5] melakukan analisis secara numerik kinerja sebuah penukar kalor pipa helikal, dimana diselidiki pengaruh dari jarak pitch dan diameter tube terhadap efektivitas penukar kalor.

Dari beberapa penelitian terkait perpindahan panas pada pipa helikal, belum ada penggunaan pada kondensor sistem destilasi minyak atsiri.Oleh karena itu,pada penelitian ini akan dirancang modelpipa helikal pada sistem kondensor minyak atsiri dengan tujuan untuk mengoptimalkan efektivitas kondensor minyak atsiri.Pada penelitian ini akan dianalisis pengaruh rasio pitch(perbandingan jarak pitch terhadap diameter tube)terhadap efektivitas kondensor sistem destilasi dengan model aliran counter flow. Metode numerik akan digunakan untuk menganalisis kinerja dari kondensor pipa helikal tersebut.

\section{BAHAN DAN METODE}

\subsection{Alat Penelitian}

Pada penelitian ini digunakan COMSOL Multiphysics 5.4 untuk melakukan simulasi aliran. Simulasi dijalankan pada PC-Desktop Windows 10 Pro 64bit dengan spesifikasi prosesor Intel ${ }^{\circledR}$ Core $^{\mathrm{TM}}$ i7-7700 @3,60GHz (8 CPUs) dan 8192MB RAM.

\subsection{Model}

Pada penelitian ini akan dirancang model kondensor dengan konstruksi sebagai berikut:

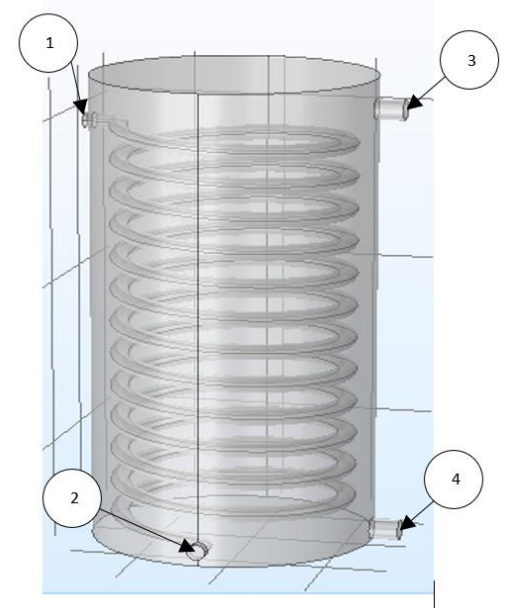

Gambar 1. Model geometri kondensor Keterangan:

1. Saluran masuk uap

2. Saluran keluar uap

3. Saluran masuk air

4. Saluran keluar air

Tabel 1. Geometrikondensor pipa helikal

\begin{tabular}{ll}
\hline Parameter & Ukuran $(\mathbf{c m})$ \\
\hline Diameter shell & 30 \\
Tinggi shell & 57 \\
Diameter tube & 1,905 \\
Jarak pitch & $4,5,6,7,8$ \\
Rasio pitch & 2,$1 ; 2,62 ; 3,15 ; 3,67 ; 4,2$ \\
Diameter koil & 24 \\
Tinggi koil & 50 \\
\hline
\end{tabular}




\subsection{Persamaan Diskritisasi}

Aliran diasumsikan weakly compressible dengan karakteristik aliran yakni laminar. Persamaan continuity, momentum, dan energy dijelaskan sebagai berikut:

$$
\begin{aligned}
& u \cdot t=0 \\
& \rho(u \cdot \nabla) u=\nabla \cdot[-p \mathrm{I}+K]+F \\
& \rho C_{p} u \cdot \nabla T+\nabla \cdot q=Q+Q_{p}+Q_{v d}
\end{aligned}
$$

\subsection{Independensi grid}

Sebelum menjalankan simulasi ditentukan kualitas dari meshing model geometri. Jumlah elemen dari masing-masing tingkat kualitas meshing diketahui sebagai berikut : extra coarser (84.364), coarser (152.931), coarse (333.383), normal (921.773), dan fine (2.258.893). Pada penelitian ini digunakan jumlah elemen sebanyak 921.773.

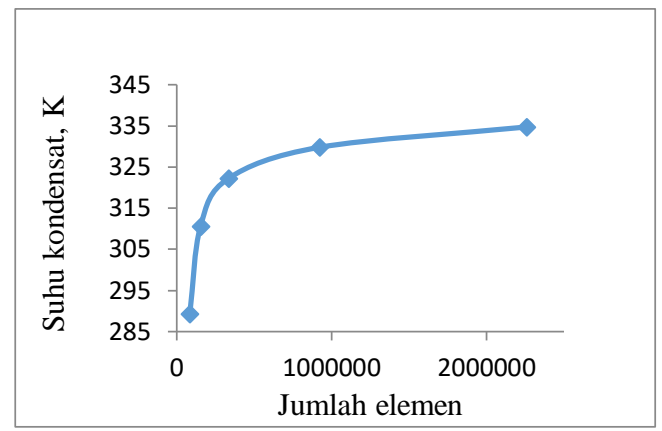

Gambar 2. Perbandingan jumlah elemen terhadap suhu kondensat yang keluar

\subsection{Data Reduksi}

\section{a. Perhitungan pada sisi dalam tube}

Menurut Fernandez-seara, et al.[2] bilangan Rayleigh pada pipa helikal dapat dihitung dengan persamaan berikut:

$$
R a=\frac{g \beta\left(T_{S}-T_{\infty}\right) d^{3}}{v^{2}}
$$

Moawed, M.[6] mendapatkan bilangan Nusselt pada pipa helikal menggunakan persamaan berikut:

$$
N u_{h}=0,0779(R a)^{0,275}\left(\frac{D}{d}\right)^{0,184}\left(\frac{p}{d}\right)^{0,212}\left(\frac{L}{d}\right)^{0,108}
$$

Untuk menghitung koefisien konveksi pada sisi dalam pipa helikal digunakan persamaan berikut:

$$
h_{i}=\frac{N u_{h} \cdot k_{h}}{L}
$$

\section{b. Perhitungan pada sisi luar tube}

Menurut Tuncer[7] bilangan Reynold pada sisi luar tube dengan bentuk helikal dapat dihitung dengan persamaan berikut:

$$
R e=\frac{\rho u D h_{\text {shell }}}{\mu_{c}}
$$

Untuk menghitung bilangan Nusselt pada sisi luar tube digunakan persamaan berikut:

$$
N u_{c}=0,6 R e^{0,5} \operatorname{Pr}_{c}{ }^{0,31}
$$

Koefisien konveksi pada sisi luar tube dihitung menggunkan persamaan berikut:

$$
h_{o}=\frac{N u_{c} \cdot k_{C}}{L}
$$

\section{c. Koefisien perpindahan panas menyeluruh}

Koefisien perpindahan panas menyeluruh dapat dideskripsikan sebagai berikut:

$$
\frac{1}{U}=\frac{1}{h_{i}}+\frac{\ln \left(\frac{d_{0}}{d_{i}}\right)}{2 \pi k_{w}}+\frac{1}{h_{0}}
$$

\section{d. Efektivitas}

Efektivitas merupakan salah satu parameter yang digunakan untuk melakukan pendekatan untuk menganalisis kinerja sebuah penukar kalor. Menurut Yan, et al.[8]. Perhitungan efektivitas dapat menggunakan persamaan berikut:

$$
\begin{aligned}
& \varepsilon=\frac{Q_{\text {aktual }}}{Q_{\max }} \\
& Q_{\text {aktual }}=U A \Delta_{L M T D} \\
& Q_{\max }=C_{\min }\left(T_{h, \text { in }}-T_{h, \text { out }}\right)
\end{aligned}
$$

Menurut Sheeba, et al.[9] $\Delta_{L M T D}$ pada aliran counter flow dapat dihitung dengan persamaan berikut:

$$
L M T D=\frac{(\mathrm{Th} 2-\mathrm{Tc} 1)-(\mathrm{Th} 1-\mathrm{Tc} 2)}{\ln ((\operatorname{Th} 2-\mathrm{Tc} 1) /(\operatorname{Th} 1-\mathrm{Tc} 2))}
$$

\section{HASIL DAN PEMBAHASAN \\ 3.1. Pengaruh Rasio Pitch}

Dari data pada Tabel 2. akan dihitung parameter-parameter perpindahan panas dari kelima variasi rasio pitch.Pada Gambar 3 ditunjukan bahwa bilangan Rayleigh meningkat seiring menningkatnya nilai rasio pitch. Hal ini diakibatkan oleh meningkatnya gradient temperatur antara dinding tube dan fluida sekeliling (air pendingin). 
Tabel 2. Data poin simulasi

\begin{tabular}{ccccccc}
\hline $\mathbf{p} / \mathbf{d}$ & $\begin{array}{c}\mathbf{T}_{\mathbf{h i}}, \\
(\mathbf{K})\end{array}$ & $\begin{array}{c}\mathbf{T}_{\mathbf{h o}}, \\
(\mathbf{K})\end{array}$ & $\begin{array}{c}\mathbf{T}_{\mathbf{h}, \mathbf{f}}, \\
(\mathbf{K})\end{array}$ & $\begin{array}{c}\mathbf{T}_{\mathbf{c i}}, \\
(\mathbf{K})\end{array}$ & $\begin{array}{c}\mathbf{T}_{\mathbf{c o}}, \\
(\mathbf{K})\end{array}$ & $\begin{array}{c}\mathbf{T}_{\mathbf{c}, \mathbf{f}}, \\
(\mathbf{K})\end{array}$ \\
\hline $\mathbf{2 , 1}$ & 373 & 329,79 & 351,470 & 288,2 & 290,70 & 289,425 \\
$\mathbf{2 , 6 2}$ & 373 & 333,78 & 353,465 & 288,2 & 290,40 & 289,275 \\
$\mathbf{3 , 1 5}$ & 373 & 337,54 & 355,345 & 288,2 & 290,22 & 289,185 \\
$\mathbf{3 , 6 7}$ & 373 & 339,9 & 356,525 & 288,2 & 290,06 & 289,105 \\
$\mathbf{4 , 2}$ & 373 & 343,39 & 358,270 & 288,2 & 289,87 & 289,010 \\
\hline
\end{tabular}

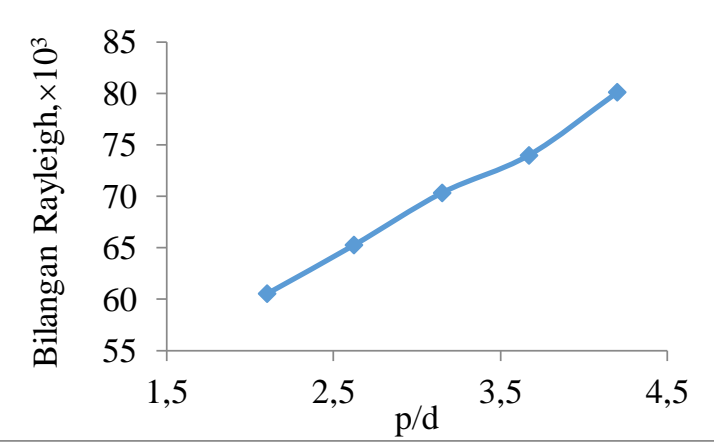

Gambar 3. Grafik bilangan Rayleigh terhadap p/d

Tren grafik yang meningkat pada bilangan Rayleigh mempengaruhi bilangan Nusselt dan koefisien perpindahan panas inner tube, dimana tren grafik kedua parameter tersebut mengalami peningkatan seiring meningkatnya nilai rasio pitch.

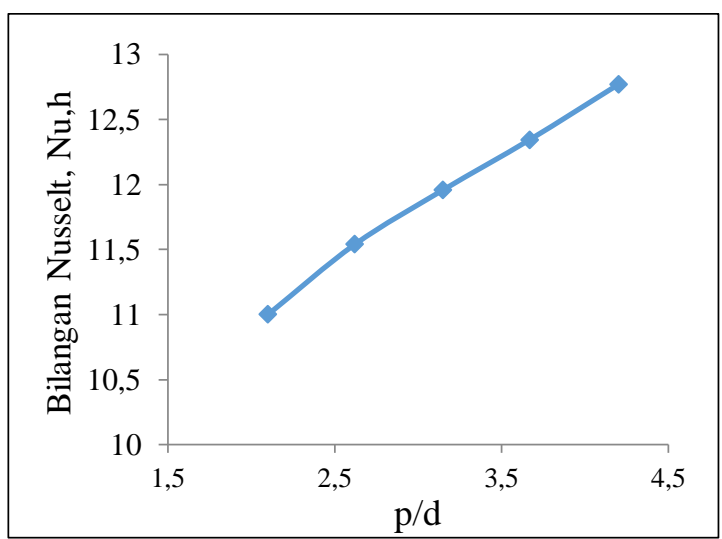

Gambar 4. Grafik bilangan Nusselt sisi dalam tube terhadap $\mathrm{p} / \mathrm{d}$

Hal tersebut dikarenakan bilangan Rayleigh berbanding lurus dengan bilangan Nusselt dan koefisien konveksi inner tube, seperti ditunjukan pada Gambar 4 dan Gambar 5.

Pada Gambar 6 menunjukan grafik bilangan Reynold mengalami peningkatan siring meningkatnya nilai rasio pitch, hal ini disebabkan oleh meningkatnya luas penampang perpindahan panas. Ketika luas penampang perpindahan panas meningkat maka akan mempengaruhi diameter hidraulik.

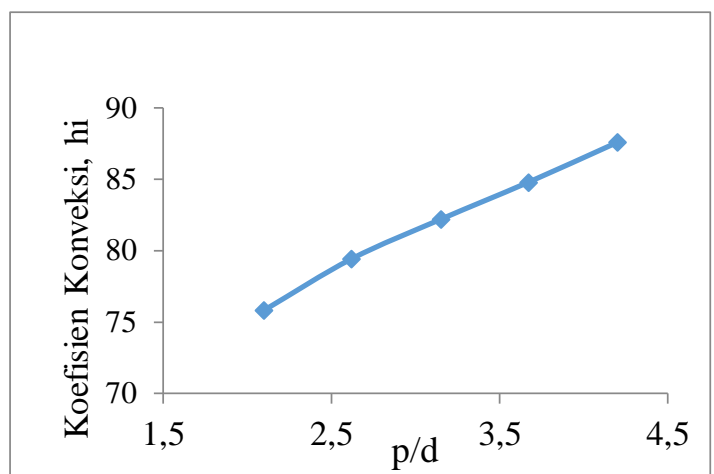

Gambar 5. Grafik koefisien konveksi sisi dalam tube terhadap $\mathrm{p} / \mathrm{d}$

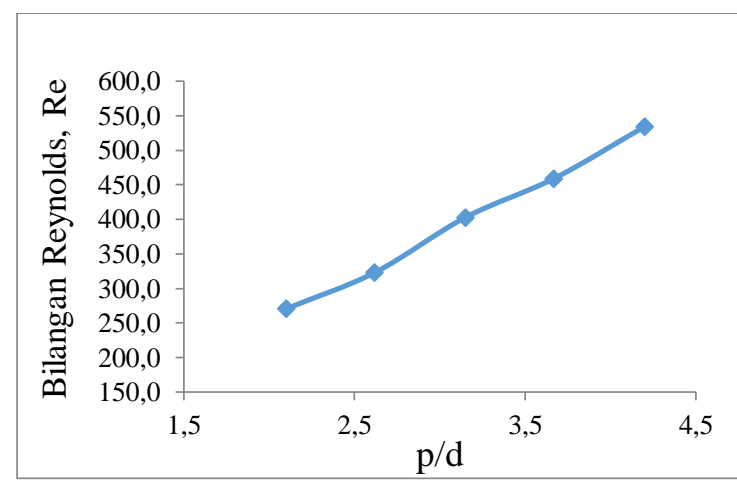

Gambar 6. Grafik bilangan Reynold terhadap p/d

Peningkatan pada nilai bilangan Reynold mempengaruhi nilai bilangan Nusselt dan koefisien konveksi sisi outer tube, dimana tren grafik menunjukan peningkatan pada pada kedua parameter seiring meningkatnya nilai rasio pitch.

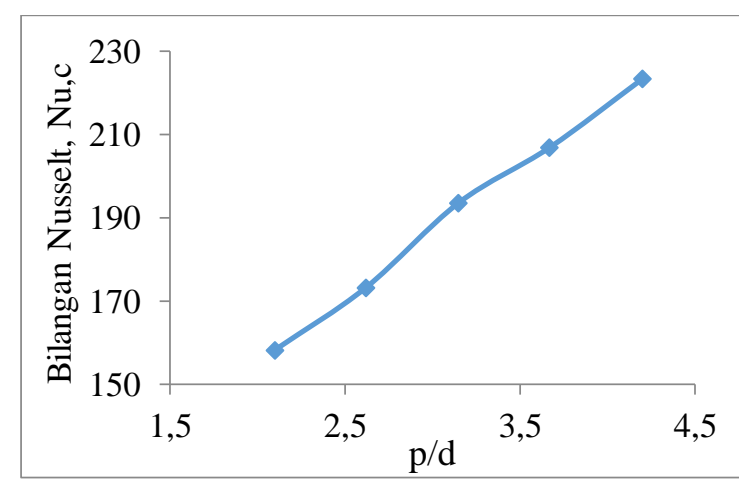

Gambar 7. Grafik bilangan Nusselt pada sisi luar tube terhadap $\mathrm{p} / \mathrm{d}$

Hal ini dikarenakan bilangan Reynold berbanding lurus dengan bilangan Nusselt dan koefisien konveksi sisi outer tube.

Peningkatan pada nilai $h_{i}$ dan $h_{o}$ akan berpengaruh pada nilai koefisien perpindahan panas menyeluruh (U). Pada gambar 9 ditunjukan bahwa nilai koefisien perpindahan panas menyeluruh (U) meningkat seiring dengan meningkatnya nilai $\mathrm{p} / \mathrm{d}$. 


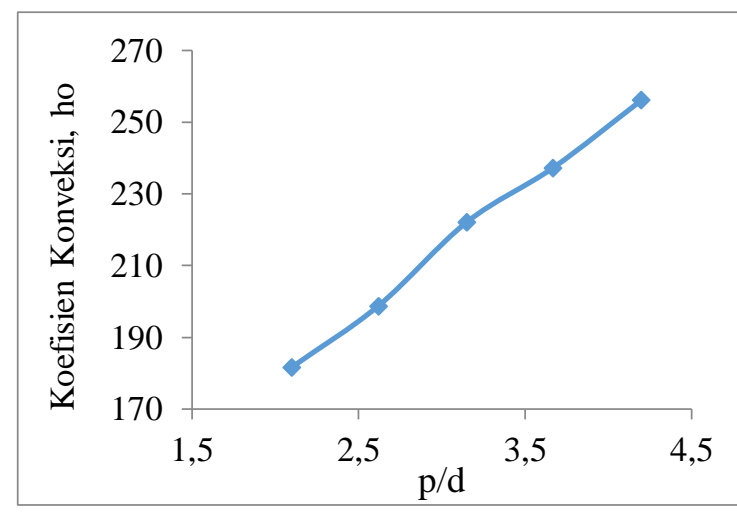

Gambar 8. Grafik koefisien konveksi sisi luar tube terhadap $\mathrm{p} / \mathrm{d}$

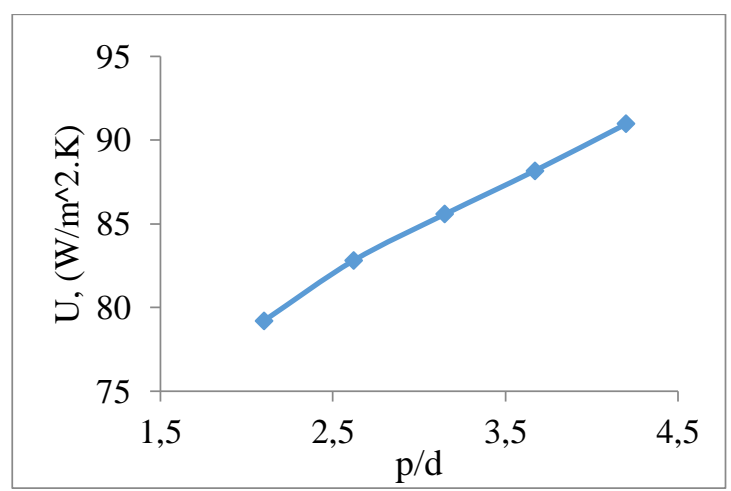

Gambar 9. Grafik perpindahan panas menyeluruh terhadap $\mathrm{p} / \mathrm{d}$

\subsection{Efektivitas}

Nilai efektivitas merupakan perbandingan dari nilai perpindahan panas aktual terhadap nilai perpindahan panas maksimum yang bisa dicapai Yan et al. [8]. Nilai efektivitas pada penelitian ini akan dibandingkan dengan penelitian terdahulu dengan konsep yang sama, dimana $\mathrm{p} / \mathrm{d}$ menjadi variabel yang divariasikan. Efektivitas tertinggi pada penelitian ini didapat pada $\mathrm{p} / \mathrm{d}=2,1$ dengan nilai $75,9 \%$ dan nilai terendah pada $\mathrm{p} / \mathrm{d}=4,2$ dengan nilai $70,7 \%$.

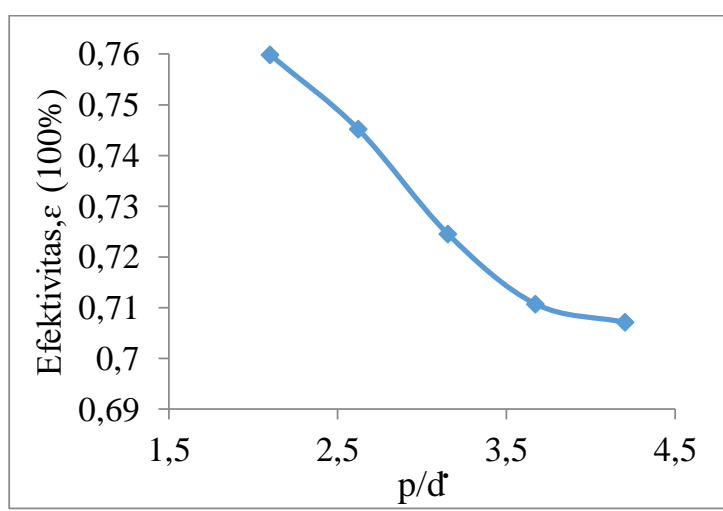

Gambar 10. Grafik efektivitas terhadap p/d

Pada Gambar 11 ditunjukan bahwa efektivitas dari model kondensor pada penelitian ini lebih tinggi dibandingkan Mirgolbabaei[8]. Hal tersebut dipengaruhi oleh fluida kerja yang digunakan. Mirgolbabaei [8] menggunakan air sebagai fluida kerja pada sisi panas dan sisi dingin, sedangkan pada penelitian ini fluida kerja yang digunakan pada sisi panas adalah uap.

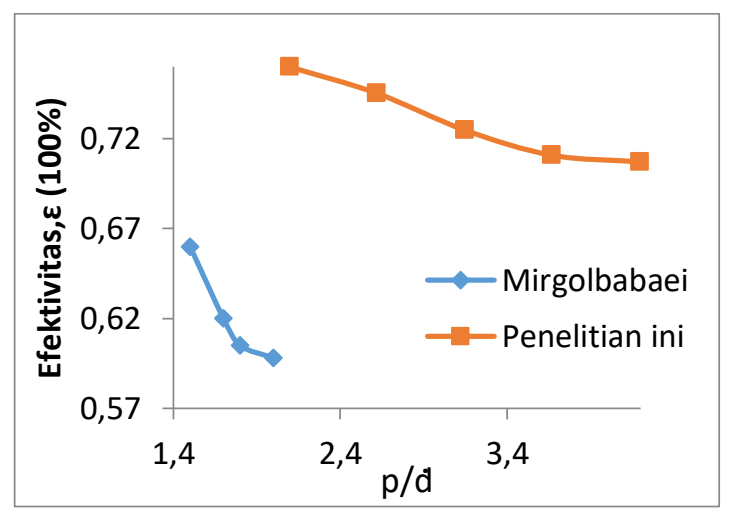

Gambar 11. Perbandingan nilai efektivitas

\section{KESIMPULAN}

Hasil analisis dengan memvariasikan nilai $\mathrm{p} / \mathrm{d}$ dan dengan nilai kecepatan masuk fluida dan temperatur masuk fluida yang konstan, dapat disimpulkan bahwa rasio pitch cukup berpengaruh pada kinerja suatu kondensor pipa helikal. Ditunjukan dengan nilai efektivitas yang semakin menurun seiring dengan meningkatnya nilai $\mathrm{p} / \mathrm{d}$.Nilai kritis dan nilai optimal dari rasio pitch ditentukan oleh fluida kerja yang digunakan pada kondensor.

\section{DAFTAR NOTASI}

p/d : Rasio pitch

$\mathrm{Ra} \quad$ : Bilangan Rayleigh

$g \quad$ : percepatan Gravitasi $\left(\mathrm{m} / \mathrm{s}^{2}\right)$

$\beta \quad$ : Koefisien Ekspansi Termal Volumetric $\left(K^{-1}\right)$

V : Viskositas kinematik fluida $\left(\mathrm{m}^{2} / \mathrm{s}\right)$

$\mathrm{T}_{\mathrm{s}} \quad$ : Temperatur permukaan $(\mathrm{K})$

$\mathrm{T}_{\infty} \quad$ : Temparatur sekeliling (K)

$\mathrm{Cp} \quad$ : Panas spesifik (J/kg.K)

$\mu \quad$ : viskositas dinamis (N.s/m²)

$\mathrm{k}$ : konduksi termal (W/m.K)

d : diameter pipa (m)

$N u_{h}$ : bilangan Nusselt pada sisi tube

$k_{h} \quad$ : konduktivitas termal fluida pada sisi tube (W/m.K)

$L \quad$ : Panjang karakteristik (m)

$\rho \quad$ : massa jenis fluida pada sisi shell $\left(\mathrm{kg} / \mathrm{m}^{3}\right)$

$u \quad$ : kecepatan aliran fluida pada sisi shell $(\mathrm{m} / \mathrm{s})$

$D_{H, \text { shell }}:$ diameter hidraulik

$\mu_{\mathrm{c}} \quad$ : viskositas dinamis (N.s $\left./ \mathrm{m}^{2}\right)$

$N u_{c} \quad$ : bilangan Nusselt pada sisi shell 
$k_{c} \quad:$ konduktivitas termal fluida pada sisi shell (W/m.K)

do : diameter outer tube $(\mathrm{m})$

di : diameter inner tube (m)

hi : koefisien konveksi inner tube $\left(\mathrm{W} / \mathrm{m}^{2} . \mathrm{K}\right)$

ho $\quad$ : koefisien konveksi outer tube $\left(\mathrm{W} / \mathrm{m}^{2} . \mathrm{K}\right)$

$k_{w} \quad:$ konduktivitas termal dinding tube $(\mathrm{W} / \mathrm{m} . \mathrm{K})$

$\varepsilon \quad$ : efektivitas

$\dot{m} \quad$ : laju aliran massa $(\mathrm{kg} / \mathrm{s})$

C : laju kapasitas panas

$\mathrm{T} \quad$ : suhu (K)

$\mathrm{V} \quad$ : Laju aliran volumetrik $\left(\mathrm{m}^{3} / \mathrm{s}\right)$

$\rho \quad:$ Densitas $\left(\mathrm{kg} / \mathrm{m}^{3}\right)$

\section{DAFTAR PUSTAKA}

[1] Moawed, M. (2005). Experimental investigation of natural convection from vertical and horizontal helicoidal pipes in HVAC applications. Energy Conversion and Management, 46(18-19), 2996-3013. [https://doi.org/10.1016/j.enconman.2005.0 2.002]

[2] Fernández-Seara, J., Piñeiro-Pontevedra, C., \& Dopazo, J. A. (2014). On the performance of a vertical helical coil heat exchanger. Numerical model and experimental validation. Applied Thermal Engineering, 62(2), 680-689.

[https://doi.org/10.1016/j.applthermaleng .2013.09.054]

[3] Alimoradi, A., \& Veysi, F. (2017). Optimal andcritical values of geometrical parameters of shell and helically coiled tube heat exchangers. Case Studies in Thermal Engineering, 10, 73-78. [https://doi.org/10.1016/j.csite.2017.03.003 ]

[4] Xu, X., Zhang, Y., Liu, C., Zhang, S., \& Dang, C. (2018). Experimental investigation of heat transfer of supercritical $\mathrm{CO} 2$ cooled in helically coiled tubes based on exergy analysis.
International Journal of Refrigeration, 89, 177-185.

[https://doi.org/10.1016/j.ijrefrig.2018.03.0 11]

[5] Mirgolbabaei, H. (2018). Numerical investigation of vertical helically coiled tube heat exchangers thermal performance. Applied Thermal Engineering, 136(February), 252-259. [https://doi.org/10.1016/j.applthermaleng.2 018.02.061]

[6] Moawed, M. (2011). Experimental study of forced convection from helical coiled tubes with different parameters. Energy Conversion and Management, 52(2), 11501156.

[https://doi.org/10.1016/j.enconman.2010.0 9.009]

[7] Tuncer, A. D., Sözen, A., Khanlari, A., Gürbüz, E. Y., \& Variyenli, H. İ. (2021). Analysis of thermal performance of an improved shell and helically coiled heat exchanger. Applied Thermal Engineering, 184.[https://doi.org/10.1016/j.applthermale ng.2020.116272]

[8] Yan, S. R., Moria, H., Pourhedayat, S., Hashemian, M., Assadi, S., Sadighi Dizaji, H., \& Jermsittiparsert, K. (2020). A critique of effectiveness concept for heat exchangers; theoretical-experimental study. International Journal of Heat and Mass Transfer, 159 , 120160.[https://doi.org/10.1016/j.ijheatmas stransfer.2020.120160]

[9] Sheeba, A., Abhijith, C. M., \& Jose Prakash, M. (2019). Experimental and numerical investigations on the heat transfer and flow characteristics of a helical coil heat exchanger. International Journal of Refrigeration, 99, 490497.[https://doi.org/10.1016/j.ijrefrig.2018. 12.002] 